\title{
Author Index Vol. 12, No. 1, 1995
}

Abrams, R.A. 73 Broelsch, C.E. 61 Fan, S.T. 5,53 Guan,R. 79 Hayashi,T. 34 Itai, Y. 22

Kang,J.Y. 79 Kawasaki, S. 40 Knoefel,W.T. 61 Liaw,Y.-F. 7 Makuuchi, M. 40 Malagó, M. 61 Miyagawa, S. 40

Nagasue, N. 34 Nagomey, D.M. 45 Ng,I.O.L. 16 Ngan,H. 65 Ohtomo,K. 22 Que,F.G. 45

Rogiers, X. 61 Sitzmann, J.V. 73 Stemeck, M. 61 Tsai,S.-L. 7 Tsui,S.-1. 53 Uchida,M. 34

Wong,J. 5 